\title{
Pancreatic Involvement in Inflammatory Bowel Disease: A Review
}

\author{
Fotios S. Fousekis ${ }^{\text {a }}$, Vasileios I. Theopistos ${ }^{\text {a }}$, Konstantinos H. Katsanos ${ }^{\text {a }}$, \\ Dimitrios K. Christodoulou ${ }^{\mathrm{a}, \mathrm{b}}$
}

\begin{abstract}
Inflammatory bowel disease (IBD) is a multisystemic disease, and pancreatic manifestations of IBD are not uncommon. The incidence of several pancreatic diseases in Crohn's disease and ulcerative colitis is more frequent compared to the general population. Pancreatic manifestations in IBD include a wide heterogenic group of disorders and abnormalities of the pancreas and range from mild self-limited diseases to severe disorders. Acute pancreatitis, chronic pancreatitis, autoimmune pancreatitis, pancreatic autoantibodies, exocrine pancreatic insufficiency and asymptomatic imaging and laboratory abnormalities are included in related-IBD pancreatic manifestations. Involvement of the pancreas in IBD may be the result of IBD itself or of medications used.
\end{abstract}

Keywords: Inflammatory bowel disease; Acute pancreatitis; Autoimmune pancreatitis; Extraintestinal manifestations; Pancreas

\section{Introduction}

Inflammatory bowel disease (IBD) is characterized by an idiopathic chronic and recurrent inflammation of the gastrointestinal tract; and Crohn's disease (CD) and ulcerative colitis (UC) compose the two major forms of IBD. Being a multisystemic disorder, both may affect many extraintestinal organs; and the frequency of extraintestinal manifestations in IBD range from $6 \%$ to $47 \%$ [1]. Pancreatic disorders and abnormalities are not uncommon in IBD patients and are often underestimated. They represent a heterogeneous group of pancreatic manifestations that includes acute pancreatitis (AP), autoimmune pancreatitis (AIP), chronic pancreatitis (CP), asymptomatic imaging abnormalities and asymptomatic elevation of pancreatic enzymes [2] (Table 1).

Manuscript submitted August 1, 2018, accepted August 21, 2018

aDepartment of Gastroenterology and Hepatology, Medical School of Ioannina, Greece

${ }^{b}$ Corresponding Author: Dimitrios K. Christodoulou, Department of Gastroenterology and Hepatology, Faculty of Medicine, University of Ioannina, Ioannina 45100, Greece. Email: dchristodoulou@gmail.com

doi: https://doi.org/10.14740/jocmr3561w

\section{Acute Pancreatitis}

\section{Epidemiology}

AP is characterized by acute inflammation and necrosis of pancreas parenchyma, and is the most frequent pancreatic disorder associated with IBD. In the general population the incidence rate of AP ranges from 10 to 44 per 100,000/year [3]; while it seems that the incidence rate of AP is higher in patients with $\mathrm{IBD}$, and particularly in patients with $\mathrm{CD}$. In a retrospective study, the cumulative incidence of AP among 5,073 IBD patients was $1.6 \%$, in a mean follow-up period of 14 years [4]; and in a study of 852 patients with $\mathrm{CD}$, the incidence rate of AP was $1.4 \%$, in a follow-up period of 10 years [5]. Also, a Danish 16-year nationwide follow-up study demonstrated elevated risk of AP both in patients with $\mathrm{CD}$ and those with UC. Standard incidence rate was $4.3 \%$ and $2.1 \%$, respectively [6]. In addition, in a population-based cohort study in Taiwan, the overall incidence of AP was 3.56-fold higher in IBD patients compared to patients without IBD [7]. Furthermore, it seems that IBD presenting as AP is more common among the pediatric population with IBD than adults with IBD. A retrospective study identified pediatric and adults patients presenting with AP as the first symptom of IBD and demonstrated that AP preceded the diagnosis of IBD in $2.17 \%(10 / 460)$ of pediatric IBD patients, compared to only $0.06 \%(2 / 3,500)$ of adult IBD patients [8].

\section{Etiology}

A wide spectrum of causes are included in pathogenesis of AP in IBD (Tables 2, 3 [4-7]). Gallstones and medications are the most common causes of AP in IBD; while it seems that postendoscopic retrograde cholangiopancreatography (ERCP), balloon enteroscopy, hypercalcemia and hypertriglyceridemia are less common causes [2]. Furthermore, consumption of alcohol is a less frequent cause of AP in IBD patients than in the general population [9].

Duodenal involvement in CD may cause AP owing to ampullary inflammation [10] or eventual reflux of the duodenal contents to the pancreatic duct due to increased intraduodenal pressure [11]. Duodenopancreatic fistula is an extremely rare complication of duodenal involvement in $\mathrm{CD}$, which causes AP [12]. Also, primary sclerosing cholangitis (PSC) is ex- 
Table 1. Pancreatic Manifestations in Inflammatory Bowel Disease

\begin{tabular}{lll} 
& Crohn's disease & Ulcerative colitis \\
Acute pancreatitis & ++ & + \\
Autoimmune pancreatitis & + & ++ \\
Chronic pancreatitis & ++ & + \\
Pancreatic insufficiency & + & ++ \\
Pancreatic autoantibodies & ++ & + \\
Benign abnormalities of pancreatic duct & + & + \\
Elevation of serum pancreatic enzymes & ++ & + \\
\hline
\end{tabular}

$(+)$ : association; $(++)$ : more frequent than other type of IBD

tremely infrequent cause of AP in IBD, mainly in UC. PSC may cause reflux of bile and sludge into the pancreatic duct due to strictures of the distal part of common bile and pancreatic ducts [13]. Also, it has been found that a quarter of patients with PSC have gallstones, increasing the risk of AP [14].

It is worth mentioning that IBD itself may predispose to AP due to hypercoagulable state of generalized inflammation, resulting pancreatic ischemia [15]. It has been found that IBD patients have 3.6-fold higher risk for thromboembolism than the general population [16].

\section{Cholelithiasis}

Cholelithiasis is one of the most common causes of AP in IBD and there is a strong association between gallstones formation and CD. Patients with large stones $(>2.5 \mathrm{~cm})$ and with small multiple stones $(<3 \mathrm{~mm})$ are at a higher risk of complications [17]. The prevalence of gallstones is higher in CD patients than in general population. Patients with $\mathrm{CD}$ have double risk for the development of gallstones. On the other hand, it seems that gallstones formation is not associated with UC [18]. Many independent parameters of CD have been related with cholelithiasis development and include ileo-colonic CD location, disease duration ( $>15$ years), extent of ileal resection ( $>$ $30 \mathrm{~cm}$ ), long hospital stay, number of hospitalizations $(>3)$, multiple total parenteral nutrition treatments, lifetime surgery and frequency of clinical recurrences ( $>3$ ) [19]. Gallstones are mainly caused by malabsorption of bile salts in ileum, which interferes with enterohepatic circulation and leads to elevation

Table 2. Studies of Acute Pancreatitis in Patients With Inflammatory Bowel Disease

\begin{tabular}{|c|c|c|c|c|}
\hline Study & Bemerjo F. et al [4] & Weber P. et al [5] & Rasmussen H.H. et al [6] & Chen Y.T. et al [7] \\
\hline Methodology & $\begin{array}{l}\text { Retrospective } \\
\text { multicentric cohort }\end{array}$ & $\begin{array}{l}\text { Retrospective } \\
\text { single center }\end{array}$ & $\begin{array}{l}\text { Danish cohort study } \\
\text { from } 1977 \text { to } 1992\end{array}$ & $\begin{array}{l}\text { Population-based } \\
\text { cohort study from } \\
2000 \text { to } 2010\end{array}$ \\
\hline Study of origin & Spain & Germany & Denmark & Taiwan \\
\hline Number of patients & 5,073 IBD patients & 852 CD patients & $\begin{array}{l}15,526 \text { IBD patients, } 3,538 \\
\text { CD patients, } 11,215 \mathrm{UC} \\
\text { patients, } 773 \text { indeterminate } \\
\text { colitis (IC) patients }\end{array}$ & 11,909 IBD patients \\
\hline \multicolumn{5}{|l|}{ Type of IBD } \\
\hline Follow-up period & 14 years & 10 years & 112,824 person-years & $5.33 \pm 3.79$ years \\
\hline Episodes of acute pancreatitis & 82 & 12 & 86 & 202 \\
\hline Incidence of acute pancreatitis & $1.6 \%$ & $1.4 \%$ & $\begin{array}{l}\text { CD patients: } 4.3 \% \text {, } \\
\text { UC patients: } 2.1 \% \text {, } \\
\text { IC patients: } 7.1 \%\end{array}$ & $\begin{array}{l}31.8 \text { per } 100,000 \\
\text { person-years }\end{array}$ \\
\hline $\begin{array}{l}\text { Number of patients with } \\
\text { acute pancreatitis (CD/UC) }\end{array}$ & 67 patients (53 CD/14 UC) & $12 \mathrm{CD}$ patients & 86 (28 CD/50 UC/8 IC) & $\begin{array}{l}202 \text { patients }(128 \\
\mathrm{CD} / 74 \mathrm{UC})\end{array}$ \\
\hline $\begin{array}{l}\text { Age of patients with } \\
\text { acute pancreatitis }\end{array}$ & $\begin{array}{l}40 \pm 12 \text { years (mean } \pm \\
\text { standard deviation) }\end{array}$ & Median $23(10-50)$ & Unknown & Unknown \\
\hline Etiology & $\begin{array}{l}63.4 \% \text { drug-induced, } \\
20.7 \% \text { idiopathic, } 12.2 \% \\
\text { cholelithiasis, } 3.7 \% \\
\text { miscellaneous causes }\end{array}$ & $\begin{array}{l}83 \% \text { unknown (common } \\
\text { causes were excluded), } \\
17 \% \text { drug-induced }\end{array}$ & Unknown & Unknown \\
\hline
\end{tabular}


Table 3. Factors Increasing the Incidence of Acute Pancreatitis in Inflammatory Bowel Disease

\begin{tabular}{l} 
Cholelithiasis \\
\hline Medications \\
Thiopurines (azathioprine/6-mercaptopourine) \\
Analogues of 5-ASA (mesalamine, sulfasalazine, olsalazine) \\
Metronidazole \\
Corticosteroids \\
Cyclosporine \\
Duodenal involvement of Crohn's disease \\
Ampullary inflammation \\
Duodenopancreatic fistula \\
Primary sclerosing cholangitis \\
Cholelithiasis \\
Strictures of common bile duct and of pancreatic ducts \\
Hypercoagulation
\end{tabular}

of enterohepatic circulation, increased biliary bilirubin levels and cholelithiasis development [20]. In addition, total parenteral nutrition and a prolonged fasting state result in reduction of gallbladder emptying, which induces development of gallstones and biliary sludge $[19,21]$.

\section{Medications}

Drug-induced AP is one of the most severe complications of IBD. Many medications such as thiopurines, corticosteroids, metronidazole and biological agents, have been implicated.

Thiopurines (azathioprine and 6-mercaptopourine) may cause more often drug-induced acute pancreatitis. AP usually occurs in the first month after thiopurine therapy and is a doseindependent adverse drug reaction [22]. The course of AP is mild and after thiopurine withdrawal, there is an immediate clinical improvement. The reported incidence of AP in IBD as a result of thiopurines ranges from $3 \%$ to $5 \%$ [23]; and it seems that the incidence is higher in patients with CD than with UC. Furthermore, female gender is associated with a 3.4-fold higher risk for development of thiopurine-induced pancreatitis (TIP) [4]; and smoking is a significant risk for azathioprine-induced AP (smokers versus non-smokers; OR: 3.24) [24].

Many pathophysiologic mechanisms of TIP have been proposed, including immunologic reactions and direct toxic effects. Genetic polymorphisms have been strongly associated with the development of thiopurine-induced pancreatitis. Particularly, patients heterozygous at rs2647087 within the class II HLA region have an estimated risk of TIP at $9 \%$ and homozygotes have $17 \%$ [25]. On the other hand, polymorphisms in TMPT (thiopurine S-methyltransferase) have been associated with dose-independent side effects, such as hepatotoxicity and myelotoxicity, but they have not been correlated with TIP [26].

Additionally, less frequently 5-aminosalicylic acid (5ASA) compounds, including sulfasalazine, olsalazine and mesalamine have been linked to the development of drug-induced
AP [27]. Most times, the course of 5-ASA-induced pancreatitis is mild. However, cases of severe necrotizing pancreatitis have been reported [28]. According to analysis of suspected serious adverse reactions reported to the Committee on Safety of Medicines of the United Kingdom, the risk of AP is 7-fold higher with mesalamine than with sulfasalazine [29]. Also, a retrospective case-control study demonstrated that the risk of AP does not differ among patients using mesalazine Multi Matrix System (MMX) or a comparator mesalazine [30]. In addition, AP may even occur after rectal 5-ASA enema administration [31]. Mesalamine-induced AP may occur from 2 days to 2 years after the start of mesalamine with most cases occurring within 6 weeks; and clinical improvement usually appearing within 4 days after mesalamine withdrawal $[23,32]$.

Drug-induced AP is an extremely rare adverse effect of biological agents and only several case reports have been described [33, 34]. In addition, a case control study showed that a combination therapy with anti-TNF is associated with lower risk of AP in IBD patients on mesalamine, thiopurines, or a combination of both [35]. Metronidazole is an antibacterial medication, which may be used in IBD treatment and also only a few case reports of metronidazole-induced AP have been reported [36]. The mechanism of metronidazole-induced pancreatitis is not unknown. It has been hypothesized that, under aerobic conditions, metronidazole may undergo redox cycling and yield hydrogen peroxide, superoxide, and other free radicals, which are toxic to $\beta$-cells. Other suggested mechanisms include immune-mediated inflammatory response and metabolic effects [37]. The time interval between metronidazole exposure and the onset of AP ranges from $12 \mathrm{~h}$ to 35 days [38]. Furthermore, AP associated with steroids and cyclosporine A is also extremely rare $[39,40]$. A Swedish population-based case-control study found that the risk of AP was increased among current users of oral glucocorticoids compared with nonusers (OR: 1.53) and the risk was higher among 4 and 14 days after drug dispensation [41].

\section{Diagnosis}

Diagnosis of AP requires the presence of at least two of the following three criteria: 1) Abdominal pain consistent with the disease; 2) Serum amylase and/or lipase greater than three times the upper limit of normal; and/or 3) Characteristic findings from abdominal imaging [42]. The definition of drug-induced AP is established, when there are the following criteria: 1) A reasonable temporal sequence between AP development and administration of the drug; 2) Withdrawal of drug causes clinical improvement; 3 ) There is re-appearance of symptoms, after re-exposure (re-challenge) [39]. In clinical practice, rechallenge is not performed (Fig. 1).

\section{Treatment}

The therapy of AP does not differ between the general population and IBD patient and the management of AP includes early aggressive intravenous fluid resuscitation, which should be titrated according to urine output and comorbidities of patient, 


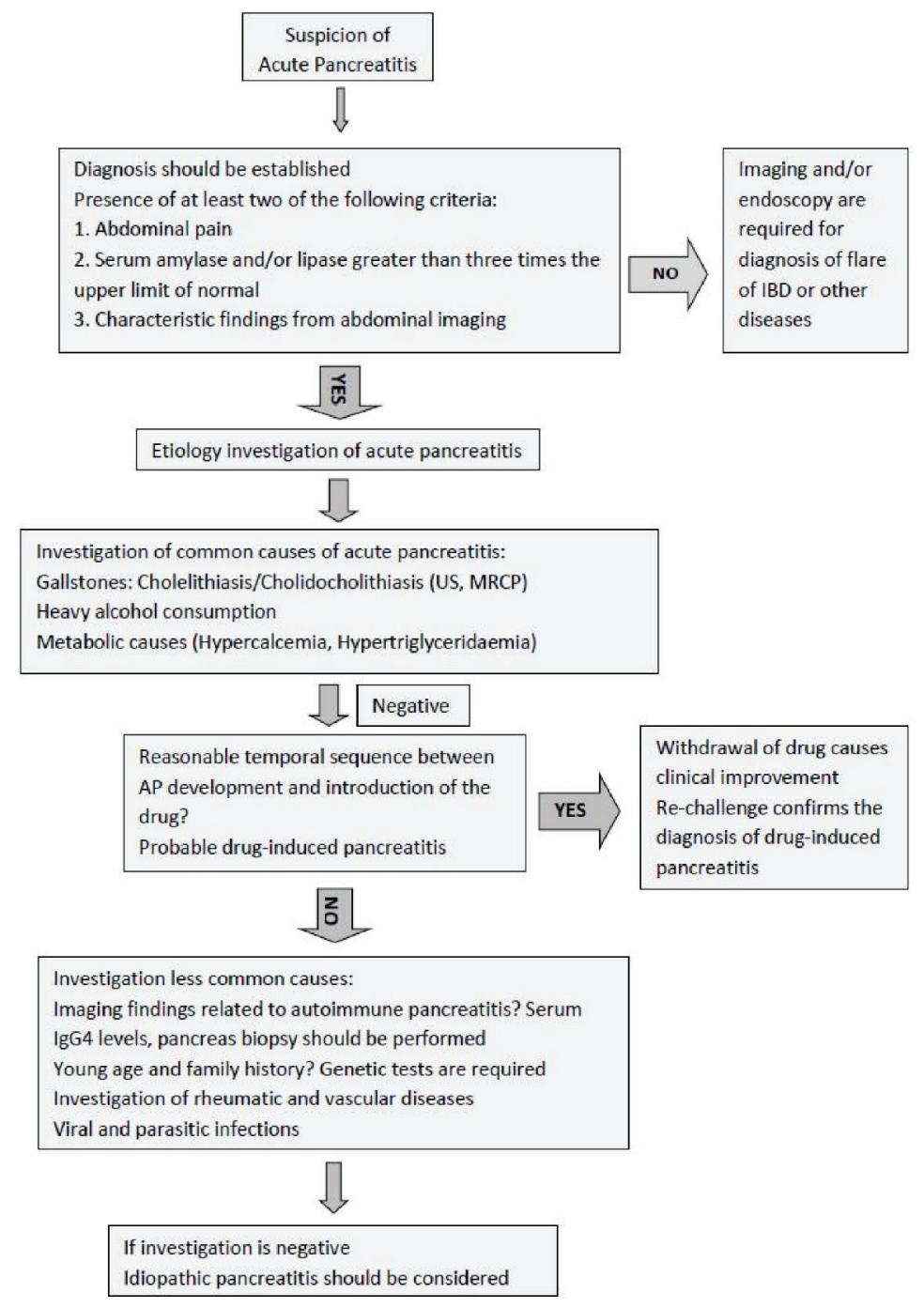

Figure 1. Diagnostic algorithm of causes of acute pancreatitis.

electrolyte replacement, bowel rest, analgesia and treatment of underlying cause and of complications of AP. When there is suspicion of drug-induced AP, immediately drug withdrawal is mandatory (Table 4) [43]. In addition, in one case, a male with ileocolonic $\mathrm{CD}$ developed idiopathic moderately severe AP during a severe flare-up of IBD. The patient received infliximab for induction remission of $\mathrm{CD}$. Clinical and endoscopic remission achieved and the course of AP was without complications [44]. Also, it is worth mentioning that the use of corticosteroids seems to be safe in patients with AP. A metaanalysis showed that corticosteroid therapy may improve outcomes in patients with severe acute pancreatitis. Therefore, corticosteroids may be used in patients with AP and exacerbation of IBD [45] (Table 4).

\section{Autoimmune Pancreatitis}

AIP is an uncommon pancreatic disease and a distinct form of pancreatitis. According to the International Consensus Diagnostic Criteria (ICDC) for autoimmune pancreatitis, AIP is characterized clinically by frequent presentation with painlessness obstructive jaundice with or without a pancreatic mass, histologically by a lymphoplasmacytic infiltrate and fibrosis and therapeutically by a dramatic response to steroids [46]. The disease is categorized into two distinct types; AIP type 1 and AIP type 2; and IBD seems to be associated with both forms, but so more with AIP type 2 .

AIP type 1 is an IgG4-related disease and characterized by elevated serum globulin G4 (IgG4) levels, histologically by lymph plasmatic infiltration, storiform fibrosis, obliterative phlebitis, and abundant ( $>10 / \mathrm{HPF}$ ) IgG4-positive plasma cells in pancreas and response to steroid therapy. On the other hand, AIP type 2 is not correlated with elevated levels of serum IgG4 and IgG4-positive plasma cells and is characterized by granulocyte epithelial lesions and response to steroid treatment. According to ICDC, AIP type 1 and type 2 may be diagnosed by assessing the combination five cardinal features: 1) Imaging findings of 
Table 4. Management of Acute Pancreatitis in Patients With Inflammatory Bowel Disease

Withdrawal of azathioprine/6-mercaptourine and 5-ASA analogues, if there is suspicion for drug-induced AP and the common causes have been excluded

Aggressive intravenous fluid resuscitation

250 - $500 \mathrm{~mL}$ per hour during the first 12 - $24 \mathrm{~h}$

Lactated Ringer's should be the preferred isotonic crystalloid fluid; it is contraindicated in hypercalcemia

Fluid administration should be titrated according to urine output and comorbidities of patient

Electrolyte replacement

Analgesia

Bowel rest

In mild AP, oral feeding can be started immediately, if there is not nausea, vomiting and abdominal pain has resolved

In several AP, enteral nutritional is recommended to prevent infectious complications

Management of complications of AP

If co-existing active IBD, infliximab and corticosteroids may be used

pancreas and pancreatic duct; 2) Levels of serum IgG4; 3 ) Other organs involvement; 4) Histopathologic findings of pancreatic parenchyma; 5) Response to steroid therapy [46, 47].

The prevalence of AIP among IBD patients is greater than in the general population mainly because there is a strong association between AIP type 2 and UC [48]. Particularly in an international multicenter survey, the prevalence of UC was $16 \%$ and of CD was $1 \%$ among 64 patients with AIP type 2, while the prevalence of UC and CD was $1 \%$ among 153 patients with AIP type 1 [49]. Additionally in a cohort study of 1,751 Japanese patients with IBD, the frequency of AIP in IBD was low and only $0.4 \%$ (five UC, two CD) of IBD patients had AIP. All patients had AIP type 2 [50]. A multicenter retrospective study analyzed data from 91 patients with IBD and AIP, compared IBD patients with and without AIP and demonstrated the impact of AIP in the natural history of IBD. Analysis showed that IBD patients with AIP had significantly fewer cases firstdegree family history of IBD and more colectomy procedures. Diagnosis of AIP preceded IBD in $20 \%$. Also, patients with UC and AIP had higher risk for colectomy (OR: 2.9) and rectal disease location (OR: 7.1); while CD patients had less perianal disease and less stricturing and less penetrating behavior, but higher risk for colectomy [51]. It is worth noting that gastroenterologists should be aware of the coexistence IgG4 colitis in AIP patients, because many patients with AIP have IgG4related colitis mimicking IBD [52].

The mechanism correlation among IBD and AIP is still unknown. However, it seems that an immune-mediated mechanism correlates AIP to other conditions, such as IBD. Because a variety of autoantibodies have been detected in patients with AIP, but none of these autoantibodies appear to be disease specific and they have been found in many other autoimmune diseases [53].

\section{Chronic Pancreatitis}

$\mathrm{CP}$ is characterized by chronic, progressive fibro-inflammation of pancreas, causing irreversible damage and impairment of exocrine and endocrine function [54]. The incidence of CP ranges from 4.4 to 11.9 per 100,000 [55]; and the $\mathrm{CP}$ is more common in males [56]. The clinical presentation of CP is varied and may include recurrent attacks of abdominal pain, diabetes mellitus, steatorrhea and malabsorption, but many patients may be asymptomatic [57]. Diagnosis of CP is frequently delayed because of non-specific symptoms as well as blood laboratory values. Imaging plays a critical role in diagnosis. The Cambridge classification grades CP according to imaging findings of MRI/CT and ERCP [58]. In addition, endoscopic ultrasound (EUS) is sensitive for diagnosing pancreatic disorders and diagnostic criteria, such as Rosemont criteria for CP, based on EUS features of pancreatic parenchyma and ducts have been developed [59].

The association between IBD and CP has been not completely investigated and there are only a few studies. In a caseseries study with 28 IBD patients (16 CD, $12 \mathrm{UC}$ ) with $\mathrm{CP}$, $\mathrm{CP}$ appeared after the onset of $\mathrm{CD}$ in $56 \%$ of cases, while in patients with UC, CP was a prior manifestation. Also, $42 \%$ of patients with UC and CP suffered from pancolitis [60]. A nationwide population-based cohort study from Taiwan compared patients with and without $\mathrm{CP}$. The overall incidence of IBD was 10.3-fold higher in patients with $\mathrm{CP}$ compared to patients without CP. Also, patients with $\mathrm{CP}$ were associated with a higher risk of IBD (HR: 6.3), mainly of CD (HR: 12.9) compared to UC (HR: 2.8) [61].

\section{Exocrine Pancreatic Insufficiency}

Exocrine pancreatic insufficiency (EPI) is characterized by reduction of pancreatic enzyme activity in the intestinal lumen, causing maldigestion [62]. EPI has been reported in IBD patients. In particular, a prospective sectional study used the fecal elastase- 1 to estimate the prevalence of EPI in IBD patients and found that $14 \%$ of patients with $\mathrm{CD}$ and $22 \%$ of patients with UC suffered from EPI. Compared to control subjects, the odds ratios (OR) for EPI were 8.34 for patients with $\mathrm{CD}$ and 12.95 for patients with UC. Also, the risk of EPI was higher 
in IBD patients with loose stools, a larger number of bowel movements per day and previous surgery [63]. In addition, another study using secretin-cerulein found that lipase was decreased in $58 \%$ of CD patients and in $80 \%$ of UC patients [64]. In a cross-sectional study with 237 unselected IBD patients, $21 \%$ of patients had reduced urinary PABA excretion $(<40 \%$ of normal values). In patients with decreased PABA test or elevated amylase or lipase than twice the upper normal limit (54 patients), a secretin test was performed, which demonstrated low bicarbonate excretion in $19 \%$ of these patients [65].

\section{Pancreatic Autoantibodies}

Antibodies against exocrine pancreas (PABs) have been described in patients with IBD. The prevalence of PABs ranges from $20 \%$ to $30 \%$ among patients with $\mathrm{CD}$ and from $2 \%$ to $9 \%$ in patients with UC [66], while the prevalence of PABs in non-IBD patients seems to be very low $(<4 \%)$ [67]. PABs belong to IgG and IgA subtypes and the major zymogen glycoprotein 2 is considered as the main target antigen of PABs [68]. It seems that anti-GP2 is associated with location and behavior of CD. In a study with 169 patients with $\mathrm{CD}$, the prevalence of IgG and IgA anti-GP2 was 30.2\%. IgG anti-GP2 were more prevalent in CD patients with stricturing behavior and perianal disease. The presence of anti-GP2 was more frequent in patients with an age at diagnosis of $\leq 16$ years (16/31) [69]. Also, another study with 225 patients with $C D$ showed that the presence of anti-GP2 is more prevalent in patients with ileal inflammation and previous surgical intervention [70]. In addition, zona pellucida-like domains-containing protein 1 (CUZD1) also belongs to PABs and it seems that anti-CUZD1 is more frequent in patients with $\mathrm{CD}$ than in $\mathrm{UC}$ and may be associated with ileocolonic and perianal disease [71].

It is worth mentioning that PABs have been detected in many diseases. Anti-GP-2 has been found in patients with active and refractory celiac disease, PSC without IBD and patients with cholangiocarcinoma [72, 73]. Therefore, the presence of PABs in IBD patients may raise diagnostic challenges.

\section{Benign Pancreatic Abnormalities}

Asymptomatic elevation of serum amylase and/or lipase is not uncommon in patients with IBD. It occurs in $8 \%$ to $21 \%$ of IBD patients and is not associated to other causes, such as renal failure, salivary gland disease or macroamylasemia [74, 75]. It seems to be not correlated with activity of IBD [76]. Possible explanations include elevation of intestinal amylase or increased amylase absorption in the inflamed gut [77]. Furthermore, pancreatic duct abnormalities have been reported in IBD patients without a history of pancreatic disease. Pancreatic duct abnormalities were found by magnetic resonance cholangiopancreatography in $16.4 \%(13 / 79)$ of patients with $\mathrm{UC}$ and none of whom had a history of overt pancreatitis [78]. Also, in another study, the rate of pancreatic duct abnormalities was $10.8 \%$ in IBD patients and there was a difference between IBD patients with or without previous pancreatitis [79].
We suggest that asymptomatic abnormal imaging findings or pancreatic enzymes do not require investigation, if the patient is asymptomatic, because they are clinically associated with little meaningful pancreatic involvement.

\section{Conclusions}

Pancreatic involvement in patients with IBD may complicate the course of IBD; and pancreatic manifestations range from innocent abnormalities of serum pancreatic enzymes and of pancreatic ducts to serious disorders, such as AP. It seems that $\mathrm{AP}$ and $\mathrm{CP}$ are more strongly associated with $\mathrm{CD}$ than with UC, while pancreatic AIP, mainly AIP type 2, occurs more often in patients with UC. Diagnosis of pancreatic disorders in IBD is not always simple, because symptoms and laboratory findings of pancreatic diseases may be attributed to IBD and clinical suspicion is often crucial. For this reason, IBD patients with symptoms pancreatic disorder should be investigated to rule out the coexistence of a pancreatic disease.

\section{Abbreviations}

AP: acute pancreatitis; AIP: autoimmune pancreatitis; CD: Crohn's disease; CP: chronic pancreatitis; EPI: exocrine pancreatic insufficiency; IBD: inflammatory bowel disease; PABs: antibodies against exocrine pancreas; PSC: primary sclerosing cholangitis; TIP: thiopurine-induced pancreatitis; UC: ulcerative colitis

\section{References}

1. Vavricka SR, Schoepfer A, Scharl M, Lakatos PL, Navarini A, Rogler G. Extraintestinal manifestations of inflammatory bowel disease. Inflamm Bowel Dis. 2015;21(8):1982-1992.

2. Ramos LR, Sachar DB, DiMaio CJ, Colombel JF, Torres J. Inflammatory bowel disease and pancreatitis: a review. J Crohns Colitis. 2016;10(1):95-104.

3. Spanier BW, Dijkgraaf MG, Bruno MJ. Epidemiology, aetiology and outcome of acute and chronic pancreatitis: an update. Best Pract Res Clin Gastroenterol. 2008;22(1):45-63.

4. Bermejo F, Lopez-Sanroman A, Taxonera C, Gisbert JP, Perez-Calle JL, Vera I, Menchen L, et al. Acute pancreatitis in inflammatory bowel disease, with special reference to azathioprine-induced pancreatitis. Aliment Pharmacol Ther. 2008;28(5):623-628.

5. Weber P, Seibold F, Jenss H. Acute pancreatitis in Crohn's disease. J Clin Gastroenterol. 1993;17(4):286-291.

6. Rasmussen HH, Fonager K, Sorensen HT, Pedersen L, Dahlerup JF, Steffensen FH. Risk of acute pancreatitis in patients with chronic inflammatory bowel disease. A Danish 16-year nationwide follow-up study. Scand J Gastroenterol. 1999;34(2):199-201.

7. Chen YT, Su JS, Tseng CW, Chen CC, Lin CL, Kao CH. 
Inflammatory bowel disease on the risk of acute pancreatitis: A population-based cohort study. J Gastroenterol Hepatol. 2016;31(4):782-787.

8. Broide E, Dotan I, Weiss B, Wilschanski M, Yerushalmi B, Klar A, Levine A. Idiopathic pancreatitis preceding the diagnosis of inflammatory bowel disease is more frequent in pediatric patients. J Pediatr Gastroenterol Nutr. 2011;52(6):714-717.

9. Moolsintong P, Loftus EV, Jr., Chari ST, Egan LJ, Tremaine WJ, Sandborn WJ. Acute pancreatitis in patients with Crohn's disease: clinical features and outcomes. Inflamm Bowel Dis. 2005;11(12):1080-1084.

10. Yung K, Oviedo J, Farraye FA, Becker JM, Andrews CW, Jr., Lichtenstein D. Ampullary stenosis with biliary obstruction in duodenal Crohn's disease: a case report and review of the literature. Dig Dis Sci. 2005;50(6):11181121.

11. Altman HS, Phillips G, Bank S, Klotz H. Pancreatitis associated with duodenal Crohn's disease. Am J Gastroenterol. 1983;78(3):174-177.

12. Pajares JA, Hernandez L, Menchen P, Menchen L. Duodenopancreatic fistula complicating upper gastrointestinal Crohn's disease: successful treatment with infliximab. Am J Gastroenterol. 2009;104(7):1863-1864.

13. Goldin E, Libson E, Wengrower D, Antal S, Kovacs Z, Rachmilewitz D. Severe acute pancreatitis as the presenting symptom of primary sclerosing cholangitis: treatment by endoscopic insertion of a biliary stent. Int Surg. 1990;75(1):58-60.

14. Said K, Glaumann H, Bergquist A. Gallbladder disease in patients with primary sclerosing cholangitis. J Hepatol. 2008;48(4):598-605.

15. Srinath AI, Gupta N, Husain SZ. Probing the association of pancreatitis in inflammatory bowel disease. Inflamm Bowel Dis. 2016;22(2):465-475.

16. Miehsler W, Reinisch W, Valic E, Osterode W, Tillinger $\mathrm{W}$, Feichtenschlager T, Grisar J, et al. Is inflammatory bowel disease an independent and disease specific risk factor for thromboembolism? Gut. 2004;53(4):542-548.

17. Sakorafas GH, Milingos D, Peros G. Asymptomatic cholelithiasis: is cholecystectomy really needed? A critical reappraisal 15 years after the introduction of laparoscopic cholecystectomy. Dig Dis Sci. 2007;52(5):13131325.

18. Zhang FM, Xu CF, Shan GD, Chen HT, Xu GQ. Is gallstone disease associated with inflammatory bowel diseases? A meta-analysis. J Dig Dis. 2015;16(11):634-641.

19. Parente F, Pastore L, Bargiggia S, Cucino C, Greco S, Molteni M, Ardizzone S, et al. Incidence and risk factors for gallstones in patients with inflammatory bowel disease: a large case-control study. Hepatology. 2007;45(5):12671274.

20. Maurer P, Haag K, Roth M, Kuder C, Scholmerich J. No evidence for abnormal gallbladder emptying in Crohn's disease. Hepatogastroenterology. 1996;43(10):807-812.

21. Pitt HA, King W, 3rd, Mann LL, Roslyn JJ, Berquist WE, Ament ME, DenBesten L. Increased risk of cholelithiasis with prolonged total parenteral nutrition. Am J Surg. 1983;145(1):106-112.
22. Ledder O, Lemberg DA, Day AS. Thiopurine-induced pancreatitis in inflammatory bowel diseases. Expert Rev Gastroenterol Hepatol. 2015;9(4):399-403.

23. Pitchumoni CS, Rubin A, Das K. Pancreatitis in inflammatory bowel diseases. J Clin Gastroenterol. 2010;44(4):246-253.

24. Teich N, Mohl W, Bokemeyer B, Bundgens B, Buning J, Miehlke S, Huppe D, et al. Azathioprine-induced acute pancreatitis in patients with inflammatory bowel diseases - a prospective study on incidence and severity. J Crohns Colitis. 2016;10(1):61-68.

25. Heap GA, Weedon MN, Bewshea CM, Singh A, Chen M, Satchwell JB, Vivian JP, et al. HLA-DQA1-HLADRB1 variants confer susceptibility to pancreatitis induced by thiopurine immunosuppressants. Nat Genet. 2014;46(10):1131-1134.

26. Liu YP, Wu HY, Yang X, Xu HQ, Li YC, Shi DC, Huang JF, et al. Association between thiopurine S-methyltransferase polymorphisms and thiopurine-induced adverse drug reactions in patients with inflammatory bowel disease: a meta-analysis. PLoS One. 2015;10(3):e0121745.

27. Garau P, Orenstein SR, Neigut DA, Kocoshis SA. Pancreatitis associated with olsalazine and sulfasalazine in children with ulcerative colitis. J Pediatr Gastroenterol Nutr. 1994;18(4):481-485

28. Faintuch J, Mott CB, Machado MC. Pancreatitis and pancreatic necrosis during sulfasalazine therapy. Int Surg. 1985;70(3):271-272.

29. Ransford RA, Langman MJ. Sulphasalazine and mesalazine: serious adverse reactions re-evaluated on the basis of suspected adverse reaction reports to the Committee on Safety of Medicines. Gut. 2002;51(4):536-539.

30. Russo L, Schneider G, Gardiner MH, Lanes S, Streck P, Rosen S. Role of pharmacoepidemiology studies in addressing pharmacovigilance questions: a case example of pancreatitis risk among ulcerative colitis patients using mesalazine. Eur J Clin Pharmacol. 2014;70(6):709-717.

31. Isaacs KL, Murphy D. Pancreatitis after rectal administration of 5-aminosalicylic acid. J Clin Gastroenterol. 1990;12(2):198-199.

32. Fernandez J, Sala M, Panes J, Feu F, Navarro S, Teres J. Acute pancreatitis after long-term 5-aminosalicylic acid therapy. Am J Gastroenterol. 1997;92(12):2302-2303.

33. Werlang ME, Lewis MD, Bartel MJ. Tumor Necrosis Factor Alpha Inhibitor-Induced Acute Pancreatitis. ACG Case Rep J. 2017;4:e103.

34. Picardo S, So K, Venugopal K, Chin M. Vedolizumabinduced acute pancreatitis: the first reported clinical case. BMJ Case Rep. 2018;2018.

35. Stobaugh DJ, Deepak P. Effect of tumor necrosis factor-alpha inhibitors on drug-induced pancreatitis in inflammatory bowel disease. Ann Pharmacother. 2014;48(10):1282-1287.

36. O'Halloran E, Hogan A, Mealy K. Metronidazole-induced pancreatitis. HPB Surg. 2010;2010:523468.

37. Sura ME, Heinrich KA, Suseno M. Metronidazole-associated pancreatitis. Ann Pharmacother. 2000;34(10):11521155 .

38. Tsesmeli NE, Giannoulis KE, Savopoulos CG, Vretou 
EE, Ekonomou IA, Giannoulis EK. Acute pancreatitis as a possible consequence of metronidazole during a relapse of ulcerative colitis. Eur J Gastroenterol Hepatol. 2007;19(9):805-806.

39. Nitsche C, Maertin S, Scheiber J, Ritter CA, Lerch MM, Mayerle J. Drug-induced pancreatitis. Curr Gastroenterol Rep. 2012;14(2):131-138.

40. Forsmark CE, Baillie J, Practice AGAIC, Economics C, Board AGAIG. AGA Institute technical review on acute pancreatitis. Gastroenterology. 2007;132(5):2022-2044.

41. Sadr-Azodi O, Mattsson F, Bexlius TS, Lindblad M, Lagergren J, Ljung R. Association of oral glucocorticoid use with an increased risk of acute pancreatitis: a population-based nested case-control study. JAMA Intern Med. 2013;173(6):444-449.

42. Tenner S, Baillie J, DeWitt J, Vege SS, American College of G. American College of Gastroenterology guideline: management of acute pancreatitis. Am J Gastroenterol. 2013;108(9):1400-1415; 1416.

43. Nesvaderani M, Eslick GD, Cox MR. Acute pancreatitis: update on management. Med J Aust. 2015;202(8):420423.

44. Triantafillidis JK, Cheracakis P, Hereti IA, Argyros N, Karra E. Acute idiopathic pancreatitis complicating active Crohn's disease: favorable response to infliximab treatment. Am J Gastroenterol. 2000;95(11):3334-3336.

45. Dong LH, Liu ZM, Wang SJ, Zhao SJ, Zhang D, Chen Y, Wang YS. Corticosteroid therapy for severe acute pancreatitis: a meta-analysis of randomized, controlled trials. Int J Clin Exp Pathol. 2015;8(7):7654-7660.

46. Shimosegawa T, Chari ST, Frulloni L, Kamisawa T, Kawa $\mathrm{S}$, Mino-Kenudson M, Kim MH, et al. International consensus diagnostic criteria for autoimmune pancreatitis: guidelines of the International Association of Pancreatology. Pancreas. 2011;40(3):352-358.

47. Uchida K, Okazaki K. Clinical and pathophysiological aspects of type 1 autoimmune pancreatitis. J Gastroenterol. 2018;53(4):475-483.

48. Tsen A, Alishahi Y, Rosenkranz L. Autoimmune pancreatitis and inflammatory bowel disease: an updated review. J Clin Gastroenterol. 2017;51(3):208-214.

49. Kamisawa T, Chari ST, Giday SA, Kim MH, Chung JB, Lee KT, Werner J, et al. Clinical profile of autoimmune pancreatitis and its histological subtypes: an international multicenter survey. Pancreas. 2011;40(6):809-814.

50. Ueki T, Kawamoto K, Otsuka Y, Minoda R, Maruo T, Matsumura K, Noma E, et al. Prevalence and clinicopathological features of autoimmune pancreatitis in Japanese patients with inflammatory bowel disease. Pancreas. 2015;44(3):434-440.

51. Lorenzo D, Maire F, Stefanescu C, Gornet JM, Seksik P, Serrero M, Bournet B, et al. Features of autoimmune pancreatitis associated with inflammatory bowel diseases. Clin Gastroenterol Hepatol. 2018;16(1):59-67.

52. Ravi K, Chari ST, Vege SS, Sandborn WJ, Smyrk TC, Loftus EV, Jr. Inflammatory bowel disease in the setting of autoimmune pancreatitis. Inflamm Bowel Dis. 2009;15(9):1326-1330.

53. Smyk DS, Rigopoulou EI, Koutsoumpas AL, Kriese S,
Burroughs AK, Bogdanos DP. Autoantibodies in autoimmune pancreatitis. Int J Rheumatol. 2012;2012:940831.

54. Majumder S, Chari ST. Chronic pancreatitis. Lancet. 2016;387(10031):1957-1966.

55. Conwell DL, Lee LS, Yadav D, Longnecker DS, Miller FH, Mortele KJ, Levy MJ, et al. American Pancreatic Association Practice Guidelines in Chronic Pancreatitis: evidence-based report on diagnostic guidelines. Pancreas. 2014;43(8):1143-1162.

56. Yadav D, Lowenfels AB. The epidemiology of pancreatitis and pancreatic cancer. Gastroenterology. 2013;144(6):1252-1261.

57. Steer ML, Waxman I, Freedman S. Chronic pancreatitis. N Engl J Med. 1995;332(22):1482-1490.

58. Schreyer AG, Jung M, Riemann JF, Niessen C, Pregler B, Grenacher L, Hoffmeister A, et al. S3 guideline for chronic pancreatitis - diagnosis, classification and therapy for the radiologist. Rofo. 2014;186(11):1002-1008.

59. Rana SS, Vilmann P. Endoscopic ultrasound features of chronic pancreatitis: A pictorial review. Endosc Ultrasound. 2015;4(1):10-14.

60. Barthet M, Hastier P, Bernard JP, Bordes G, Frederick J, Allio S, Mambrini P, et al. Chronic pancreatitis and inflammatory bowel disease: true or coincidental association? Am J Gastroenterol. 1999;94(8):2141-2148.

61. Chen YL, Hsu CW, Cheng CC, Yiang GT, Lin CS, Lin $\mathrm{CL}$, Sung FC, et al. Increased subsequent risk of inflammatory bowel disease association in patients with chronic pancreatitis: a nationwide population-based cohort study. Curr Med Res Opin. 2017;33(6):1077-1082.

62. Lindkvist B. Diagnosis and treatment of pancreatic exocrine insufficiency. World J Gastroenterol. 2013;19(42):7258-7266.

63. Maconi G, Dominici R, Molteni M, Ardizzone S, Bosani M, Ferrara E, Gallus S, et al. Prevalence of pancreatic insufficiency in inflammatory bowel diseases. Assessment by fecal elastase-1. Dig Dis Sci. 2008;53(1):262-270.

64. Angelini G, Cavallini G, Bovo P, Brocco G, Castagnini A, Lavarini E, Merigo F, et al. Pancreatic function in chronic inflammatory bowel disease. Int J Pancreatol. 1988;3(23):185-193.

65. Heikius B, Niemela S, Lehtola J, Karttunen T, Lahde S. Pancreatic duct abnormalities and pancreatic function in patients with chronic inflammatory bowel disease. Scand J Gastroenterol. 1996;31(5):517-523.

66. Soubieres AA, Poullis A. Emerging role of novel biomarkers in the diagnosis of inflammatory bowel disease. World J Gastrointest Pharmacol Ther. 2016;7(1):41-50.

67. Joossens S, Vermeire S, Van Steen K, Godefridis G, Claessens G, Pierik M, Vlietinck R, et al. Pancreatic autoantibodies in inflammatory bowel disease. Inflamm Bowel Dis. 2004;10(6):771-777.

68. Bogdanos DP, Rigopoulou EI, Smyk DS, Roggenbuck D, Reinhold D, Forbes A, Laass MW, et al. Diagnostic value, clinical utility and pathogenic significance of reactivity to the molecular targets of Crohn's disease specific-pancreatic autoantibodies. Autoimmun Rev. 2011;11(2):143148.

69. Bogdanos DP, Roggenbuck D, Reinhold D, Wex T, Pav- 
lidis P, von Arnim U, Malfertheiner P, et al. Pancreaticspecific autoantibodies to glycoprotein 2 mirror disease location and behaviour in younger patients with Crohn's disease. BMC Gastroenterol. 2012;12:102.

70. Pavlidis P, Romanidou O, Roggenbuck D, Mytilinaiou MG, Al-Sulttan F, Liaskos C, Smyk DS, et al. Ileal inflammation may trigger the development of GP2-specific pancreatic autoantibodies in patients with Crohn's disease. Clin Dev Immunol. 2012;2012:640835.

71. Michaels MA, Jendrek ST, Korf T, Nitzsche T, Teegen B, Komorowski L, Derer S, et al. Pancreatic autoantibodies against CUZD1 and GP2 are associated with distinct clinical phenotypes of Crohn's disease. Inflamm Bowel Dis. 2015;21(12):2864-2872.

72. Gross S, Bakker SF, van Bodegraven AA, van Hoogstraten IM, Gelderman KA, Bouma G, Mulder CJ, et al. Increased $\operatorname{IgA}$ glycoprotein-2 specific antibody titres in refractory celiac disease. J Gastrointestin Liver Dis. 2014;23(2):127-133.

73. Tornai T, Tornai D, Sipeki N, Tornai I, Alsulaimani R, Fechner K, Roggenbuck D, et al. Loss of tolerance to gut immunity protein, glycoprotein 2 (GP2) is associated with progressive disease course in primary sclerosing cholangitis. Sci Rep. 2018;8(1):399.

74. Tromm A, Holtmann B, Huppe D, Kuntz HD, Schwegler U, May B. [Hyperamylasemia, hyperlipasemia and acute pancreatitis in chronic inflammatory bowel diseases]. Leber Magen Darm. 1991;21(1):15-16, 19-22.

75. Katz S, Bank S, Greenberg RE, Lendvai S, Lesser M, Napolitano B. Hyperamylasemia in inflammatory bowel disease. J Clin Gastroenterol. 1988;10(6):627-630.

76. Bokemeyer B. Asymptomatic elevation of serum lipase and amylase in conjunction with Crohn's disease and ulcerative colitis. Z Gastroenterol. 2002;40(1):5-10.

77. Garrido Gomez E, Lopez San Roman A, Bermejo San Jose F. Idiopathic pancreatitis in inflammatory bowel disease. J Crohns Colitis. 2008;2(3):237-240.

78. Toda N, Akahane M, Kiryu S, Matsubara Y, Yamaji Y, Okamoto M, Minagawa N, et al. Pancreas duct abnormalities in patients with ulcerative colitis: a magnetic resonance pancreatography study. Inflamm Bowel Dis. 2005;11(10):903-908.

79. Barthet M, Lesavre N, Desplats S, Panuel M, Gasmi M, Bernard JP, Dagorn JC, et al. Frequency and characteristics of pancreatitis in patients with inflammatory bowel disease. Pancreatology. 2006;6(5):464-471. 